\title{
Substrate Specificity and Biochemical Characteristics of an Engineered Mammalian Chondroitinase ABC
}

\author{
Philippa M. Warren,* James W. Fawcett, and Jessica C. F. Kwok
}

Cite This: ACS Omega 2021, 6, 11223-11230

Read Online

ABSTRACT: Chondroitin sulfate proteoglycans inhibit regeneration, neuroprotection, and plasticity following spinal cord injury. The development of a second-generation chondroitinase ABC enzyme, capable of being secreted from mammalian cells ( $\mathrm{mChABC}$ ), has facilitated the functional recovery of animals following severe spinal trauma. The genetically modified enzyme has been shown to efficiently break down the inhibitory extracellular matrix surrounding cells at the site of injury, while facilitating cellular integration and axonal growth. However, the activity profile of the enzyme in relation to the original bacterial chondroitinase (bChABC) has not been determined. Here, we characterize the activity profile of $\mathrm{mChABC}$ and compare it to bChABC, both enzymes having been maintained under physiologically relevant conditions for the duration of the experiment. We show that this genetically modified enzyme can be secreted reliably and robustly in high yields from a mammalian cell line. The modifications

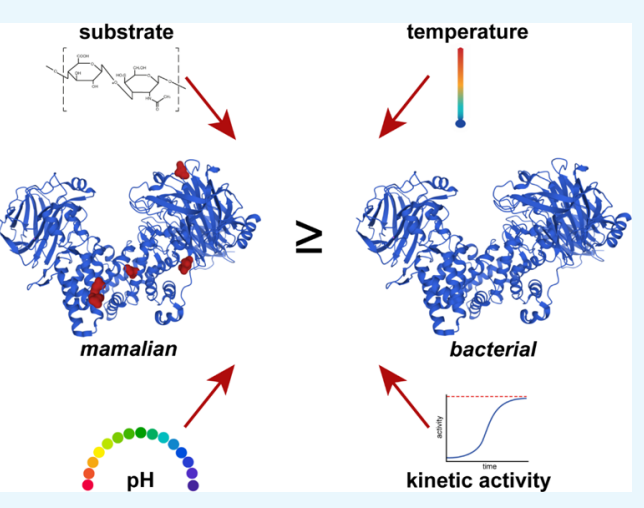
made to the cDNA of the enzyme have not altered the functional activity of mChABC compared to bChABC, ensuring that it has optimal activity on chondroitin sulfate- $\mathrm{A}$, with an optimal $\mathrm{pH}$ at 8.0 and temperature at $37^{\circ} \mathrm{C}$. However, mChABC shows superior thermostability compared to bChABC, ensuring that the recombinant enzyme operates with enhanced activity over a variety of physiologically relevant substrates and temperatures compared to the widely used bacterial alternative without substantially altering its kinetic output. The determination that mChABC can function with greater robustness under physiological conditions than $\mathrm{bChABC}$ is an important step in the further development of this auspicious treatment strategy toward a clinical application.

\section{INTRODUCTION}

Promoting functional and anatomical regeneration following spinal cord injury (SCI) is therapeutically challenging. A major obstacle to any form of recovery is the inhibitory environment that develops around the lesion site, dominated by the presence of chondroitin sulfate proteoglycans. ${ }^{1-3}$ The bacterial enzyme chondroitinase $\mathrm{ABC}$ ( $\mathrm{bChABC}$ ) acts by cleaving the chondroitin sulfate-glycosaminoglycan (CS-GAG) chains into their component disaccharides and subsequently removing what is considered to be the major inhibitory component of these macromolecules. $^{4-7}$ Treatment using this enzyme (originally isolated fromProteus vulgaris) has been successful at promoting plasticity and regeneration in vivo and in vitro following experimental SCI in a number of different models. ${ }^{8-17}$ However, several factors limit the clinical use of the enzyme in vivo. For example, bChABC is temperaturesensitive, losing most activity within 3 to 10 days at $37^{\circ} \mathrm{C}$. ${ }^{18,19}$ For the more severe SCIs, a single bolus injection of the enzyme is not sufficient to yield functional recovery, ${ }^{20-22}$ and a more invasive treatment or repeated administration is required, such as intrathecal infusion or secretion of the enzyme from an implanted biomaterial. ${ }^{23-26}$

Gene therapy has often been used to facilitate the experimental sustained delivery of therapeutic molecules through in vivo or ex vivo strategies. Cafferty et al. ${ }^{27}$ demonstrated these techniques in vivo through the transgenic expression of $\mathrm{bChABC} \mathrm{cDNA}$ in mouse reactive astrocytes under the GFAP promoter, facilitating the decrease of CSGAGs at the site of SCI. However, the $N$-glycosylation system in eukaryotes has limited the secretion of the bacterial enzyme in mammalian cells. ${ }^{27}$ A recombinant form of bChABC capable of being transduced and secreted in an active form from mammalian cells $(\mathrm{mChABC})$ has been developed through the mutagenesis of key $\mathrm{N}$-glycosylation sites on the molecule. ${ }^{28,29}$ Recently, it has been shown that targeting this mChABC construct to axons can promote neurite extension in vitro. ${ }^{30}$ Using a lenti-viral version of $\mathrm{mChABC}$, we have shown that enzyme-transduced Schwann cells are able to migrate and intermingle within astrocytic boundaries, facilitating neurite outgrowth in vitro and in vivo. ${ }^{29}$ Following acute lenti-viral

Received: December 24, 2020

Accepted: March 30, 2021

Published: April 19, 2021 

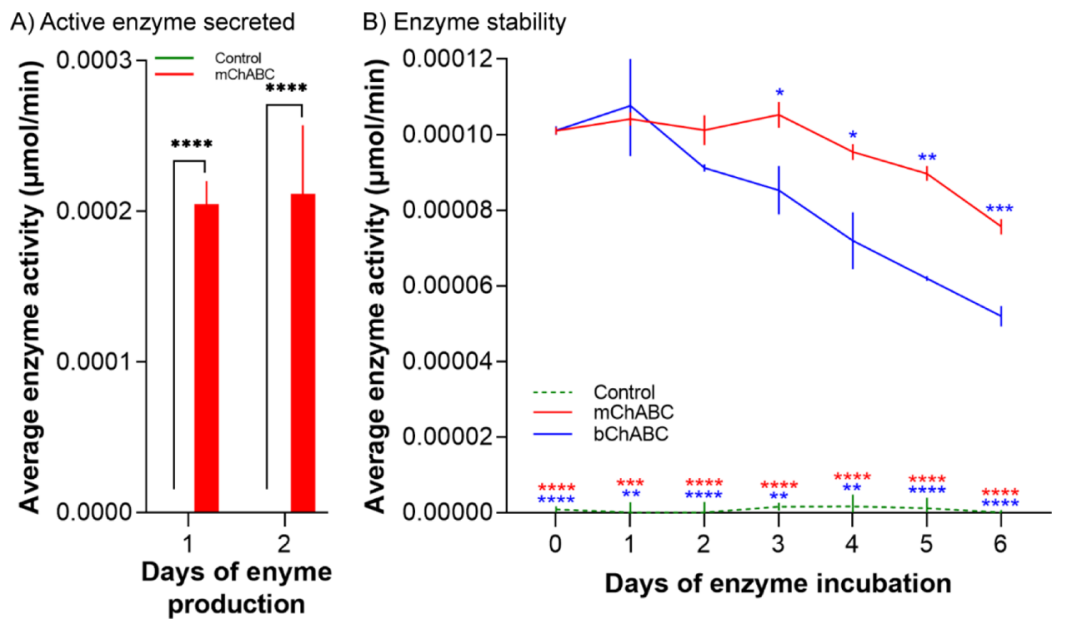

Figure 1. Amount and stability of active mChABC secreted by HEK293 cells. (A) Average amount of active mChABC secreted from HEK293 over a $24 \mathrm{~h}$ period for 2 consecutive days following transfection $(N=3$ from independent cell batches). (B) Stability of $0.0001 \mu \mathrm{mol} / \mathrm{min} \mathrm{mChABC}$ over a period of 6 days at $37^{\circ} \mathrm{C}(\mathrm{N}=3$ from independent cell batches $)$. For both panels, data show means \pm SD.

Table 1. Activity of Commercial bChABC and mChABC Acting on GAG Substrates ${ }^{a}$

\begin{tabular}{lcccc}
\multicolumn{1}{c}{ substrate } & average $\mathrm{MW}(\mathrm{kDa})$ & control $\left(\mu \mathrm{mol} \mathrm{min}^{-1} \mathrm{mg}^{-1}\right)$ & $\mathrm{mChABC}\left(\mu \mathrm{mol} \mathrm{min}^{-1} \mathrm{mg}^{-1}\right)$ & $\mathrm{bChABC}\left(\mu \mathrm{mol} \mathrm{min}^{-1} \mathrm{mg}^{-1}\right)$ \\
CS-A from bovine trachea & 12 & $0.0558 \pm 0.000185$ & $4.69 \pm 0.00614$ \\
DS from porcine intestinal mucosa & 16 & $0.0264 \pm 0.000573$ & $2.57 \pm 0.0086$ \\
CS-C from shark cartilage & 35 & $0.0147 \pm 0.00019$ & $3.57 \pm 0.00436$ \\
Hyaluronan & 215 & $0.0117 \pm 0.000173$ & $0.444 \pm 0.00131$
\end{tabular}

${ }^{a}$ Enzyme activity measured as $\mathrm{U} / \mathrm{mg}$ of protein $\left(\mu \mathrm{mol} \mathrm{min}{ }^{-1} \mathrm{mg}^{-1}\right)$. Values show means $\pm \mathrm{SD}$ and shown to three significant figures. The experiment was conducted at $\mathrm{pH} 8$ and $37^{\circ} \mathrm{C}(\mathrm{N}=3$ for each condition from independent cell batches). Sigma bChABC was preincubated at 37 ${ }^{\circ} \mathrm{C}$ for $48 \mathrm{~h}$ prior to assessment. $\mathrm{MW}=$ molecular weight.

transduction into the injured spinal cord, mChABC was shown to be secreted, active, and able to produce functional sprouting and motor recovery up to 10 weeks following trauma in vivo. $^{31,32}$ In combination with the development of viral technology, mChABC has recently been expressed successfully in an immune-evasive regulatable adeno-associated viral vector under doxycycline induction. ${ }^{32}$ This provides an important pathway for the potential translation of $\mathrm{ChABC}$ in gene therapy. However, neither the biochemical characteristics of $\mathrm{mChABC}$ under physiologically relevant conditions nor the relationship it has with those of the commercial bChABC has been determined. This is despite in vitro and in vivo evidence that the recombinant enzyme may be more effective than bChABC. ${ }^{29}$

It is important to assess the characteristics of $\mathrm{mChABC}$ to determine if it operates effectively in conditions likely to be experienced within the human body. These data may impact the development of the $\mathrm{mChABC}$ construct for clinical treatments. Furthermore, it is important to determine if the modifications made to the recombinant enzyme have caused alterations in its potential activity and effectiveness. Here, we use transfection of a plasmid-mChABC to show the ease of enzyme expression in, and secretion from, mammalian cells. We report the optimal biochemical conditions and enzyme kinetics for the secreted $\mathrm{mChABC}$ enzyme under physiologically relevant conditions and demonstrate that the recombinant enzyme has superior functionality than $\mathrm{bChABC}$ due to increased thermostability.

\section{RESULTS AND DISCUSSION}

Transfection of HEK293 Cells Yields High Quantities of Thermostable mChABC. In order to assess the activity of mChABC, HEK293 cells were transfected with the plasmid mChABC ( $p$-mChABC) construct through nucleofection (Supporting Information Figure S1A-C). The concentrated lysate was collected over $24 \mathrm{~h}$ following transfection and assessed for $\mathrm{mChABC}$ activity using the cetylpyridinium chloride (CPC) turbidity assay. A population of $2 \times 10^{6}$ cells transfected with $p$-mChABC consistently produced a yield of $0.0002 \mu \mathrm{mol} / \mathrm{min}$ active enzyme as compared to control populations, which yielded no such activity (Figure 1A). The day of collection following transfection did not affect the amount of the active enzyme produced $[\mathrm{F}(1,4)=0.0163, p=$ 0.905, two-way ANOVA with post-hoc Turkey], suggesting that the cells can regularly secrete similar amounts of the molecule over time. To assess the stability of the enzyme, $0.0001 \mu \mathrm{mol} / \mathrm{min}$ of $\mathrm{mChABC}$ and $\mathrm{bChABC}$ was incubated at $37{ }^{\circ} \mathrm{C}$ for 6 days with activity measured daily. The secreted mChABC was shown to have superior thermostability in culture medium compared to the commercially available $\mathrm{bChABC}$, remaining at a plateau of activity for 5 rather than 2 days and exhibiting less loss of total activity over time [Figure 1B; $\mathrm{F}(12,36)=19.2, P<0.0001$, two-way ANOVA post-hoc Turkey]. These data demonstrate that biologically active $\mathrm{mChABC}$ is expressed and secreted from transfected cells with high stability.

Biochemical Characterization of mChABC Activity. Having established mChABC expression in HEK293 cells, the optimal biochemical conditions to achieve maximal activity of the mammalian enzyme were determined and assessed against 


\section{pH specificity}

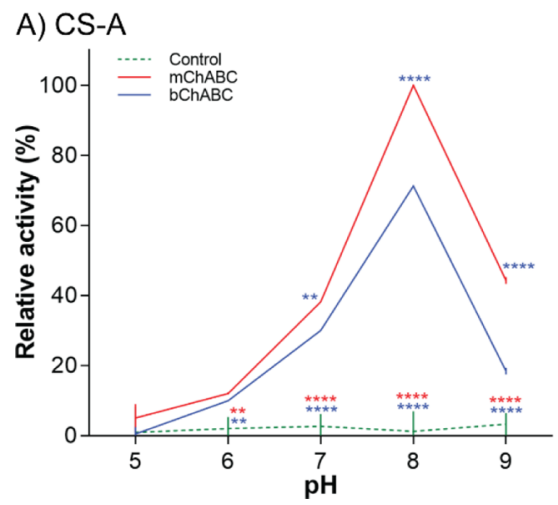

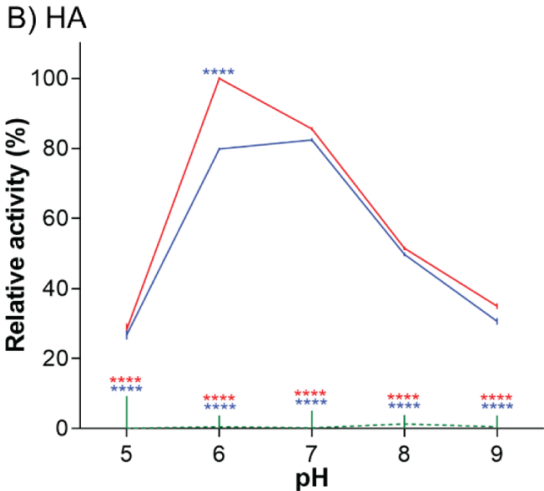

Figure 2. $\mathrm{pH}$ specificity of mChABC compared to bChABC. Effect of $\mathrm{pH}$ on enzyme activity when incubated with (A) CS-A and (B) hyaluronic acid (HA). For both panels, data show means $\pm \mathrm{SD}$ and $N=3$ (from independent cell batches).
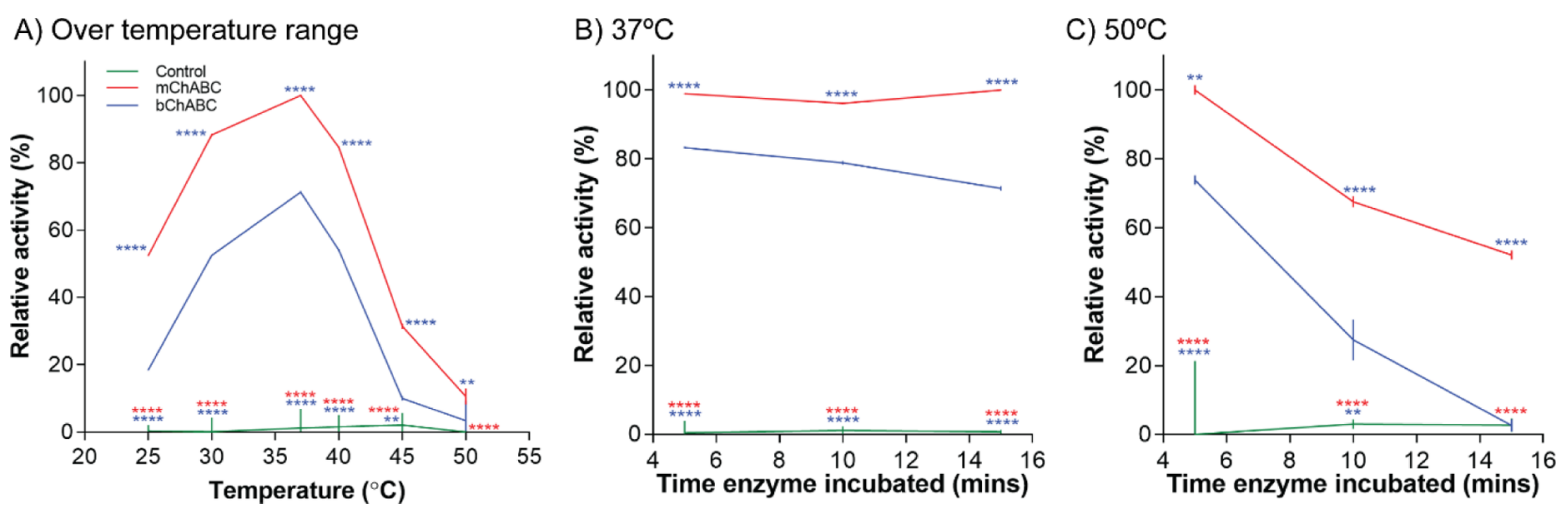

Figure 3. Temperature specificity of $m C h A B C$ compared to bChABC. Effect of temperature on enzyme activity using CS-A at pH 8 over (A) a temperature range, and preincubation of the enzyme at (B) $37^{\circ} \mathrm{C}$ and $(\mathrm{C}) 50{ }^{\circ} \mathrm{C}$ to assess thermostability. For all panels, data show means $\pm \mathrm{SD}$ and $N=3$ (from independent cell batches).

the commercially available bChABC. These parameters included substrate specificity, $\mathrm{pH}$, temperature, and thermostability. To ensure accuracy when comparing the mChABC and $b C h A B C$, the commercial enzyme was placed under the same conditions as the recombinant enzyme for the same length of time [Dulbecco's modified Eagle's medium (DMEM) with sodium pyruvate and ITS+, at $37^{\circ} \mathrm{C}$ for $24 \mathrm{~h}$, centrifuged, EDTA-free protease inhibitor cocktail added, concentrated, and quantity of the active enzyme assessed through the CPC turbidity assay].

Optimal Substrate. Concentrations of $0.5 \mu \mathrm{g} / \mu \mathrm{L}$ active $\mathrm{mChABC}$ and bChABC were determined using the CPC turbidity assay and used to assess the activity of the ChABCs on CS-A, -C, DS, and HA (Table 1; Supporting Information Figure S2). These data showed that both the specific ChABC used $[\mathrm{F}(2,24)=555,836, P<0.0001$, two-way ANOVA with post-hoc Bonferroni] and the substrate under consideration $[\mathrm{F}(3,24)=205,278, P<0.0001$, two-way ANOVA with posthoc Bonferroni] affected the degree of enzyme activity. Interestingly, both $\mathrm{mChABC}$ and $\mathrm{bChABC}$ exhibited minimal levels of activity on $\mathrm{HA}$ at $\mathrm{pH}$ 8.0, showing no difference from control $(P=\mathrm{ns}$; Table 1$)$. However, $\mathrm{mChABC}$ showed activity on CS-A, CS-C, and DS, which was $\sim 25 \%$ higher than that achieved with the bChABC (Table $1 ; P<0.0001$ in all comparisons). Both $\mathrm{mChABC}$ and bChABC showed an $\sim 25 \%$ decrease in activity using CS-C and $\sim 50 \%$ reduction with DS substrates as compared to CS-A (Table 1), 6,33,34 clearly establishing the latter as the optimal substrate. These data confirm that the modifications to $\mathrm{mChABC}$ have not altered the enzyme substrate binding properties, explaining why it has effects similar to the commercial enzyme in vivo. However, $\mathrm{mChABC}$ shows greater activity than the bacterial enzyme under the same conditions.

Optimal $\mathrm{pH}$. The $\mathrm{pH}$ range at which the enzymes maximally operate was evaluated using both CS-A and HA as substrates and the relative activity reported as compared to the maximum obtained. $\mathrm{mChABC}$ and $\mathrm{bChABC}$ showed activity greater than the control in all experimental conditions (Figure 2). Both enzymes exhibited a relatively narrow $\mathrm{pH}$-activity profile of $\pm 0.5 \mathrm{pH}$ around the optimum $\mathrm{pH} 8.0$ on CS-A [Figure 2A; $\mathrm{F}(4,30)=446.7, P<0.0001$, two-way ANOVA with post-hoc Turkey]. However, mChABC showed $\sim 25 \%$ greater activity compared to the bChABC over this $\mathrm{pH}$ range $[\mathrm{F}(2,30)=$ 591.3, $P<0.0001$, two-way ANOVA with post-hoc Turkey]. These data again suggest that the engineered $\mathrm{mChABC}$ enzyme functions more effectively than the commercial alternative. The optimum activity on $\mathrm{HA}$ for both ChABCs occurred at $\mathrm{pH} 6.0$ [Figure 2B; $\mathrm{F}(4,30)=345.2, P<0.0001$, two-way ANOVA with post-hoc Turkey]. ${ }^{4,6,33-35}$ Both $\mathrm{mChABC}$ and $\mathrm{bChABC}$ were relatively active over a wider $\mathrm{pH}$ range than displayed on $\mathrm{CS}-\mathrm{A}(\mathrm{pH} \mathrm{5-8)}$, although enzyme activity was substantially reduced (Figure 2B; Table 1). Interestingly, when outside the optimal $\mathrm{pH}$ range (and thus under different conditions from those in Table 1), mChABC showed increased activity on HA compared to bChABC $[P<$ 0.0001 ; Figure $2 \mathrm{~B} ; \mathrm{F}(2,30)=1678, P<0.0001$, two-way 
ANOVA with post-hoc Turkey]. These data show that mChABC may function better under the physiological conditions of the mammalian body than bChABC. All subsequent assays were performed at the optimized $\mathrm{pH} 8.0$ on CS-A.

Optimal Temperature. We showed that both the specific ChABC used $[\mathrm{F}(2,36)=2468, P<0.0001$, two-way ANOVA with post-hoc Turkey] and the temperature at which the assay is conducted $[\mathrm{F}(5,36)=596.1, P<0.0001$, two-way ANOVA with post-hoc Turkey] affected enzyme activity (Figure 3 ). Both mChABC and bChABC showed optimal activity at the physiological temperature of $37^{\circ} \mathrm{C}$ (Figure 3A). Furthermore, the activity profile of the two enzymes over the temperature range was similar with an $\sim 40 \%$ increase in relative activity over $25-37{ }^{\circ} \mathrm{C}$, and a rapid decline in activity as temperatures increased. Indeed, the ChABC enzymes showed an $\sim 50 \%$ loss in relative activity in temperatures exceeding $40{ }^{\circ} \mathrm{C}$. However, consistent with our previous data, $\mathrm{mChABC}$ showed an $\sim 25 \%$ greater relative activity than $\mathrm{bChABC}$ across this temperature range (Figure 3A; minimum $P<0.01$ ). This is again indicative of the greater activity and stability of the recombinant enzyme, suggesting that it may be more effective than the commercial alternative in vivo.

To determine if the rapid decline in $\mathrm{mChABC}$ and $\mathrm{bChABC}$ relative activity at higher temperatures was caused by irreversible denaturation, the enzymes were incubated for 5 , 10 , and $15 \mathrm{~min}$ at 37 or $50{ }^{\circ} \mathrm{C}$ and then transferred to $37^{\circ} \mathrm{C}$ for data acquisition (Figure 3B,C). Interestingly, data show that mChABC was relatively stable at $37{ }^{\circ} \mathrm{C}$, more so than $\mathrm{bChABC}$, the latter showing a gradual decline in relative activity with continued incubation (Figure $3 \mathrm{~B}$; variation due to the enzyme used $\mathrm{F}(2,18)=14,404, P<0.0001$; variation due to time $\mathrm{F}(2,18)=17.02, P<0.0001$, two-way ANOVA with post-hoc Turkey). The trends in data are also shown at $50{ }^{\circ} \mathrm{C}$ [Figure 3C; variation due to the enzyme used $\mathrm{F}(2,18)=203.1$, $P<0.0001$; variation due to time $\mathrm{F}(2,18)=61.93, P<0.0001$, two-way ANOVA with post-hoc Turkey]. Under these conditions, the relative activity of mChABC falls by $\sim 25 \%$ for every $5 \mathrm{~min}$ of incubation. The decline in bChABC activity is far more rapid with a $\sim 45 \%$ decrease for every $5 \mathrm{~min}$ of incubation, occurring under minimal baseline conditions following $15 \mathrm{~min}$ incubation $(P=0.9998$; Figure 3C). These data suggest that denaturation is a factor in ChABC activity at temperatures above $40{ }^{\circ} \mathrm{C}$ and that $\mathrm{mChABC}$ is more thermostable than the commercial enzyme at all physiologically relevant temperatures assessed.

mChABC Kinetic Activity. Kinetic parameters were determined for the engineered $\mathrm{mChABC}$ enzyme and compared to the commercial bChABC (Table 2). The kinetic

Table 2. Kinetic Analysis of $\mathrm{mChABC}$ and Commercial bChABC $^{a}$

$\begin{array}{cccc}\text { enzyme } & K_{\mathrm{m}}(\mu \mathrm{M}) & k_{\text {cat }}\left(\mathrm{min}^{-1}\right) & \begin{array}{c}k_{\text {cat }} / K_{\mathrm{m}} \\ \left(\mu \mathrm{M}^{-1} \mathrm{~min}^{-1}\right)\end{array} \\ \begin{array}{c}\text { no enzyme } \\ \text { control }\end{array} & -0.0384 \pm 0.147 & 0.163 \pm 0.0372 & -4.24 \\ \text { mChABC } & 0.527 \pm 0.0523 & 46.1 \pm 0.874 & 84.5 \\ \begin{array}{c}\text { bChABC } \\ \text { (Sigma) }\end{array} & 0.373 \pm 0.0318 & 37.1 \pm 0.544 & 99.4\end{array}$

${ }^{a}$ Values show means $\pm \mathrm{SD} . K_{\mathrm{m}}$ and $k_{\text {cat }}$ are shown to three significant figures and $k_{\text {cat }} / K_{\mathrm{m}}$ to 1 decimal place. $N=8$ for each condition (from independent cell batches). parameters used to characterize enzyme activity each showed differences due to the enzyme used. This included the concentration of the substrate leading to half-maximal velocity $\left[K_{\mathrm{m}} ; \mathrm{F}(2,21)=471.5, P<0.0001\right.$, one-way ANOVA with posthoc Turkey] the number of substrate molecules the enzyme converts to product per unit time $\left[k_{\text {cat }} ; \mathrm{F}(2,21)=13,428, P<\right.$ 0.0001 , one-way ANOVA with post-hoc Turkey]; and the catalytic efficiency $\left[k_{\mathrm{cat}} / K_{\mathrm{m}} ; \mathrm{F}(2,21)=135.1, P<0.0001\right.$, oneway ANOVA with post-hoc Turkey]. mChABC showed a decrease in CS-A binding affinity $\left(K_{\mathrm{m}}\right)$ compared to bChABC (Table 2). However, the engineered enzyme showed a large increase $(P<0.0001)$ in values describing the catalytic center of activity $\left(k_{\text {cat }}\right)$. This means that mChABC may bind with slightly less frequency to the substrate than bChABC. However, following binding, $\mathrm{mChABC}$ catabolizes the molecule with greater frequency than bChABC. For this reason, there is no significant difference between the catalytic efficiency $\left(k_{\text {cat }} / K_{\mathrm{m}}\right)$ of $\mathrm{mChABC}$ and bChABC $(P=0.216$; Table 2), suggesting that the reaction rate of the enzymes is similar under optimal conditions.

We have established the biochemical characteristics of a mammalian-compatible $\mathrm{ChABC}$ in direct comparison with the commercial bacterial alternative. We show that delivery of the recombinant $\mathrm{mChABC}$ into $\mathrm{mChABC}$ leads to high expression and secretion of the active enzyme in vitro. The resulting $\mathrm{mChABC}$ produced was shown to have superior biological activity on a variety of physiological substrates, while maintaining the enzymes optimal temperature and $\mathrm{pH}$ range. While the genetic alterations made to $\mathrm{mChABC}$ were shown to modify individual components of the enzyme catalytic reaction, ultimately its kinetic capacity is no different from the commercially available bChABC. However, we demonstrate that due to superior thermostability, $\mathrm{mChABC}$ has significantly greater activity then $\mathrm{bChABC}$ under physiological conditions, supporting its use in vivo and continued development as a clinical treatment.

The large-scale expression and secretion of active mChABC from cell lines has not previously been shown. We demonstrate that $\mathrm{mChABC}$ is secreted in high yields in $\mathrm{mChABC}$ over consecutive days under physiological conditions. Active bacterial $\mathrm{ChABC}$ has been secreted from $\mathrm{mChABC}$ following the removal of the hydrophobic leader sequence. ${ }^{36,37}$ However, the yield of active ChABC in this form was modest in comparison to that reported here. ${ }^{37}$ Similarly, chondroitinase $\mathrm{AC}(\mathrm{ChAC})$ can be endogenously secreted in an active form from $\mathrm{mChABC}$ in vitro and in vivo. ${ }^{38,39}$ Unfortunately, activity characterization of ChAC showed only modest enzyme yield and specific activities on both CS-A and CS- $\mathrm{C}^{40}$ in comparison to the values, which we report for $\mathrm{mChABC}$. Moreover, ChAC does not act on DS, which is expressed in the spinal cord following injury, ${ }^{41}$ reducing the enzyme's effectiveness as a potential SCI treatment. Importantly, we show activity of $\mathrm{mChABC}$ is superior to $\mathrm{bChABC}$ and other known secreted forms of chondroitinase on all sulfates (CS-A, DS, and CS-C), which predominate in the normal and injured $\mathrm{CNS}^{42}$ This would suggest that the specific modifications made to mChABC cDNA facilitate optimal enzyme secretion and activity within physiological in vitro and in vivo conditions.

We demonstrate that $\mathrm{mChABC}$ operates optimally under the same physiological temperature and $\mathrm{pH}$ profile as bChABC. ${ }^{4,6,33-35}$ Moreover, the kinetic profile of $\mathrm{mChABC}$ activity shows that the enzymes substrate binding affinity has been reduced, but the catalytic activity of the enzyme has 
increased as compared to $\mathrm{bChABC}$. This ensures that the catalytic efficiency exhibited by $\mathrm{mChABC}$ is similar to the commercial enzyme. ${ }^{4,6,33-35,43}$ However, we uniquely demonstrate that the activity of $\mathrm{mChABC}$ significantly exceeded that of the commercial bChABC under optimal physiological conditions due to increased thermostability. mChABC is stable in vitro over 3 day at $37{ }^{\circ} \mathrm{C}$, far greater than $24 \mathrm{~h}$ achieved by bChABC. ${ }^{18}$ The modifications made to mChABC appear to achieve similar levels of thermostabilization as yielded by those of trehalose. ${ }^{44}$ These data may explain why the modified enzyme has functioned better than the bacterial alternative in vivo ${ }^{31,32,45}$ and the increase in cellular integration and neurite outgrowth caused by $\mathrm{mChABC}$ in vitro and in vivo when compared to bChABC acting under the same conditions. $^{29}$ The increased thermostability exhibited by $\mathrm{mChABC}$ further promotes the use of this second-generation enzyme over the commercially available bChABC.

\section{CONCLUSIONS}

$\mathrm{mChABC}$ can be reliably and robustly produced from mammalian cell lines. This modified enzyme operates with the same efficiency, optimally under the same physiological conditions, and upon identical substrates as the commercial bacterial enzyme. However, the modified mChABC has increased thermostability at physiologically relevant temperatures, increasing the enzyme functional output compared to the widely used bChABC. These findings support the development of mChABC as a treatment for SCI and other pathological diseases as well as extending our knowledge concerning the expression of prokaryotic genes in eukaryotes.

\section{EXPERIMENTAL SECTION}

Institutional ethical approval was not required for these experiments, and the study was not preregistered. The recombinant form of bChABC used in this study (mChABC) was based on clone Y133 with mutations at $N$-glycosylation sites Asn 675,282, 345, 515 (S-A), and 715. Please see the study by Muir et al. for further details regarding the modifications made. ${ }^{28,30}$

Cell Culture Reagents. DMEM with and without phenol red and fetal calf serum (FCS) were purchased from Thermo Fisher Scientific. Penicillin/streptomycin/fungizone (PSF; $2 \%)$, trypsin, and poly-D-lysine were purchased from Sigma, while ITS+ (Insulin-transferrin-sodium selerite with bovine serum albumin and linoleic acid; 1:100) was from $\mathrm{BD}$ Bioscience. Bacterial chondroitinase ABC (Sigma) was used in a buffer containing $50 \mathrm{mM}$ Tris base and $50 \mathrm{mM}$ sodium acetate ( $\mathrm{pH} 8.0$; Sigma). Cell counts were conducted using a Countess automated cell counter (Thermo Fisher Scientific).

Culture and Transfection of HEK293 Cells. Human embryonic kidney (HEK293) cells were procured from frozen stock populations, thawed, and grown in supplemented DMEM [DMEM with $10 \%$ FCS, $2 \%$ penicillin/streptomycin/amphotericin, bovine pituitary extract (Sigma, $10 \mu \mathrm{g} / \mathrm{mL}$ ) ] at $37^{\circ} \mathrm{C}$ with $7 \% \mathrm{CO}_{2}$ and passaged at a ratio of $1: 10$ every 48 $\mathrm{h}$ (or when $70 \%$ confluent) using $0.1 \%$ trypsin to avoid senescence and increased cell numbers. Stock populations were validated from the producer prior to freezing and underwent no more than 15 passages before being replaced with new stock population. Flasks of cells were assigned to experimental groups using simple randomization, and the experimenter was blind to the treatment groups at all stages of the experiment and analysis.

HEK293 cells were transfected with a Nucleofector (Lonza; program A-23) using Cell Line Nucleofector Kit V (Lonza). Briefly, $2 \times 10^{6}$ cells were trypsinized and resuspended in solution with $5 \mu \mathrm{g}$ of $p$-mChABC-mCherry, $p$-mChABC, or $p$ mCherry DNA. Following transfection, cells were incubated at $37{ }^{\circ} \mathrm{C}$ with $7 \% \mathrm{CO}_{2}$ and expression of the desired $\mathrm{mChABC}$ protein was assessed through immunohistochemistry and the CPC turbidity assay. The rate of cell division and transfection efficiency were determined though immunohistochemistry. The total number of cells was determined through Hoechst33342 (1:10,000; Sigma) staining, while counter staining with Ki67 (1:200; AbCam) following cellular fixation in $4 \%$ paraformaldehyde (Sigma) using previously defined methodology. ${ }^{29}$ Cells were analyzed under fluorescent microscopy (Leica6000).

For the extraction of secreted $\mathrm{mChABC}$, cells were washed and the medium was replaced with DMEM (without phenol red) supplemented with sodium pyruvate $(1: 1000)$ and ITS+ (1:100). The medium was collected over the following $24 \mathrm{~h}$ with each sample centrifuged to remove cellular debris and EDTA-free protease inhibitor cocktail (Roche) added to ensure any target proteins were not cleaved by endogenous cellular proteases. The remaining supernatant was concentrated ( $50 \mathrm{~K}$ centricon; Millipore) and stored at $-20{ }^{\circ} \mathrm{C}$ until required for experimentation.

CPC Turbidity Assay. Using a modified and validated form of the CPC assay, ${ }^{25,29} 5 \mu \mathrm{L}$ of samples from transfected cells was incubated with $50 \mu \mathrm{L}$ of chondroitin sulfate A (CS-A; 20 $\mu \mathrm{g}$; Sigma) at $37^{\circ} \mathrm{C}$ for $30 \mathrm{~min}$ and then denatured at $95{ }^{\circ} \mathrm{C}$. $20 \mu \mathrm{L}$ of each sample was incubated with an equal volume of the CPC reagent $[1: 1$ of $0.2 \%(\mathrm{w} / \mathrm{v}) \mathrm{CPC}$ and $133 \mathrm{mM}$ magnesium chloride; Fluka]. Absorbance was measured at 405 $\mathrm{nm}$ using a $\mu$ Quant Microplate Spectrophotometer (Biotek Instruments), and data were adjusted for baseline based on the negative control. Addition of DNase (Thermo Fisher Scientific) failed to alter optical density data. Using a calibration curve generated with known quantities of bChABC (Sigma), the quantity of the active enzyme in each sample was determined based on the measured absorbance. Calculations were assessed through three separate experiments where, in each, five known concentrations of the enzyme were accurately calculated using this methodology. ${ }^{29}$

Characterization of ChABC Activity. Enzyme activity was defined as the amount of the product formed by an enzyme per milligram of the total protein $\left(\mu \mathrm{mol} \mathrm{min} \mathrm{mg}^{-1}\right)$. Solutions were made in $50 \mathrm{mM}$ Tris $-\mathrm{HCl}\left(\mathrm{p} K_{\mathrm{a}}=8.06\right)$ and 50 $\mathrm{mM} \mathrm{NaAc}$ buffer. This buffer was utilized in all experiments as per manufacturers' guidance to facilitate the activity of bChABC (Sigma Aldrich), as it could accommodate a large pH range. ${ }^{6,33}$ Samples of mChABC from transfected HEK293 cells (collected over $24 \mathrm{~h}$ ) or bChABC (each $2 \mu \mathrm{L}$ at $0.5 \mu \mathrm{g} /$ $\mu \mathrm{L}$ as determined through the CPC turbidity assay) were mixed in an excess of the GAG substrate $(400 \mu \mathrm{L}$ at $1 \mathrm{mg} / \mathrm{mL})$ in a quartz cuvette. The cuvette was immediately placed in a temperature-controlled spectrophotometer (Lambda $35 \mathrm{UV} /$ VS spectrometer, Perkin Elmer), and change in absorbance was monitored every $0.2 \mathrm{~ms}$ for $5 \mathrm{~min}$ at $232 \mathrm{~nm}$, a wavelength corresponding to the absorbance of disaccharides produced from enzymatic activity. ${ }^{6,33,43}$ Enzyme samples were kept on ice prior to the commencement of the assay, while the substrate was prewarmed to the temperature at which the 
experiment was conducted. A $2 \mu \mathrm{L}$ sample of buffer solution was assessed as a negative control. All commercial bChABC enzymes were incubated in DMEM (without phenol red) for $24 \mathrm{~h}$ at $37{ }^{\circ} \mathrm{C}$ prior to analysis, so as to match the environmental conditions of the mChABC. Quantities of all active enzymes used were determined using the CPC turbidity assay and protein concentration assessed by absorbance at 280 $\mathrm{nm}$ on the spectrophotometer.

To acquire enzyme activity, absorbance was corrected for background based on the negative control. The rate of absorbance change was calculated by linear regression (Prism). This was converted to concentration and enzyme activity assessed through Beer-Lamberts Law [rate of absorbance change $=$ molar absorption coefficient $(\varepsilon) \times$ concentration $\times$ cuvette path length], assuming that the chemical equilibrium remained constant. $\varepsilon$ of $\mathrm{ChABC}$ is $3800 \mathrm{M}^{-1} \mathrm{~cm}^{-1,6,33,43}$ and experiments were carried out at a $1 \mathrm{~cm}$ path length. The protocol described was validated using Seikagaku bChABC (not used in further experiments, as it is no longer commercially available), and the values obtained were consistent with those reported in the literature. ${ }^{4,6,33-35}$

To characterize mChABC activity, the enzyme was assessed under of a variety of conditions to determine substrate specificity, optimal $\mathrm{pH}$ and temperature, and enzyme kinetics.

Substrate Specificity. Determined using four GAG substrates: CS-A from bovine trachea (Sigma), dermatan sulfate (DS or CS-B) from porcine intestinal mucosa (Sigma), CS-C from shark cartilage (Sigma), and hyaluronan (HA; of medium molecular weight-250 $\mathrm{kDa}$ ) from Streptococcus pyogenes $(\mathrm{R} \& \mathrm{D})$.

Optimal $\mathrm{pH}$, Temperature, and Thermostability. The influence of $\mathrm{pH}$ was investigated on CS-A and $\mathrm{HA}$ at $37^{\circ} \mathrm{C}$ in five $\mathrm{pHs}(\mathrm{pH}$ 5.0, 6.0, 7.0, 8.0, and 9.0). Optimal temperature was assessed by varying the temperature at which the reaction occurred on CS-A at six intervals $(25,30$, $37,40,45$, and $50{ }^{\circ} \mathrm{C}$ ). To determine thermostability, the enzyme activity on CS-A at $37^{\circ} \mathrm{C}$ was measured after enzyme preincubation for 5,15 , and $30 \mathrm{~min}$ at 37 and $50{ }^{\circ} \mathrm{C}$.

Enzyme Kinetics. CS-A was dissolved at eight concentrations $(0.0,0.01,0.02,0.05,0.1,0.3,0.5$, and $1.0 \mathrm{mg} / \mathrm{mL})$ in reaction buffer at $\mathrm{pH} 8.0$, and initial reaction rates were recorded every $0.2 \mathrm{~ms}$ for $5 \mathrm{~min}$ at $37{ }^{\circ} \mathrm{C}$. The data were interpreted using linear regression analysis (GraphPad Prism). The initial rate of reaction $(\nu 0)$ was determined from the value of the slope from the plot of product formation as a function of time. This value was corrected for background based on the negative control. By analyzing the rate of reaction change at each substrate concentration using Michaelis-Menten equations (with Briggs-Haldane alterations; GraphPad Prism), the components of enzyme kinetics were calculated. This includes the maximal/limiting velocity of an enzyme, as substrate concentration gets large $\left(V_{\max }\right)$, the concentration of the substrate leading to half-maximal velocity $\left(K_{\mathrm{m}}\right)$, and the number of substrate molecules each enzyme site converts to product per unit time $\left(k_{\text {cat }}\right)$. The values of $V_{\max }$ and $K_{\mathrm{m}}$ were extracted from the Hanes plot generated by monitoring the product formation and using the equation: $[\mathrm{S}] / \nu=K_{\mathrm{m}} / V_{\mathrm{m}}+$ $[\mathrm{S}] / V_{\mathrm{m}}$, where $K_{\mathrm{m}}$ represents the substrate concentration at half saturation and $[\mathrm{S}]$ the substrate concentration. $k_{\text {cat }}$ was calculated using the equation $V_{\max }=k_{\text {cat }} \times[\mathrm{E}]$, where [E] represents total enzyme concentration. From these values, the catalytic efficiency $\left(k_{\mathrm{cat}} / K_{\mathrm{m}}\right)$ was determined.
Statistics. Power analysis using $\mathrm{G}^{*}$ Power was conducted prior to all experiments to ensure that sample sizes used were sufficient to yield reliable data based on known standard deviations to determine the expected effect size, level of acceptable significance, and type 1 error threshold $(\alpha) \leq 0.05$ and power $(1-\beta) \geq 0.90$. All experiments were analyzed blind to the experimental condition, and none were excluded based on the outcome. A minimum of three repeats were conducted for each experiment with separate samples being collected from independent cell culture preparations per condition. The parameters were compared between the control and the test group using either the one- or two-way analysis of variance (ANOVA) with post-hoc Turkey or Bonferroni (defined in the text; GraphPad Prism v9). Divergences were considered significant if $P<0.05$. Significance values represented as $*=P<0.05, * *=P<0.01$, *** $=P<$ 0.001 , and $* * * *=P<0.0001$. Data show means \pm SD.

\section{ASSOCIATED CONTENT}

\section{Supporting Information}

The Supporting Information is available free of charge at https://pubs.acs.org/doi/10.1021/acsomega.0c06262.

Figures showing expression and secretion of active mChABC-mCherry from HEK293 cells and the chemical structure of chondroitin sulfate A (CS-A), chondroitin sulfate B (dermantan sulfate, DS), chondroitin sulfate $\mathrm{C}$ (CS-C), and hyaluronan (hyaluronic acid, HA) (PDF)

\section{Accession Codes}

Bacterial chondroitinase ABC-UniProtKB P59807.

\section{AUTHOR INFORMATION}

\section{Corresponding Author}

Philippa M. Warren - Department of Clinical Neurosciences, John van Geest Centre for Brain Repair and Department of Physiology, Development and Neuroscience, University of Cambridge, Cambridge CB2 OPY, U.K.; Wolfson Centre for Age Related Diseases, Institute of Psychiatry, Psychology and Neuroscience, King's College London, London SE1 1UL, U.K.; ๑ orcid.org/0000-0002-9910-1156; Phone: (0) 2078486170; Email: philippa.warren@kcl.ac.uk

\section{Authors}

James W. Fawcett - Department of Clinical Neurosciences, John van Geest Centre for Brain Repair, University of Cambridge, Cambridge CB2 OPY, U.K.; Centre for Reconstructive Neuroscience, Institute of Experimental Medicine, Czech Academy of Sciences, 14220 Prague 4, Czech Republic

Jessica C. F. Kwok - Department of Clinical Neurosciences, John van Geest Centre for Brain Repair, University of Cambridge, Cambridge CB2 OPY, U.K.; Centre for Reconstructive Neuroscience, Institute of Experimental Medicine, Czech Academy of Sciences, 14220 Prague 4, Czech Republic; School of Biomedical Sciences, Faculty of Biological Sciences, University of Leeds, Leeds LS2 9JT, U.K.

Complete contact information is available at:

https://pubs.acs.org/10.1021/acsomega.0c06262

\section{Author Contributions}

J.W.F. and J.C.F.K.co-senior author. Biochemical work, cell culture, immunohistochemistry, data analysis, and data 
processing were performed by P.M.W. while J.W.F. and J.C.F.K. provided technical information and experimental support. Manuscript preparation and editing were performed by P.M.W. with the edits of J.W.F. and J.C.F.K. The project was conceived and designed by P.M.W., J.C.F.K., and J.W.F.

\section{Funding}

This work was supported by a Natalie Rose Barr Studentship from the International Spinal Research Trust (NRB0083) and King's Prize Fellowship to PMW, project grants from International Spinal Research Trust, Wings for Life, and European Union-the Operational Programme Research, Development and Education in the framework of the project "Centre of Reconstructive Neuroscience," registration number CZ.02.1.01/0.0./0.0/15_003/0000419 to JCFK, and Medical Research Council UK research grant (MR/S011110/1) to PMW and JCFK.

\section{Notes}

The authors declare no competing financial interest.

Correspondence and requests for the material should be addressed to P.M.W., philippa.warren@kcl.ac.uk. The data sets generated and/or analyzed during the current study are available from the corresponding author on reasonable request.

\section{ACKNOWLEDGMENTS}

The authors thank Prof. Roger Keynes, Dr. Elizabeth Muir, Dr. Aviva Tolkovsky, and Dr. John Rogers for their support and assistance with the work.

\section{REFERENCES}

(1) Properzi, F.; Asher, R. A.; Fawcett, J. W. Chondroitin sulphate proteoglycans in the central nervous system: changes and synthesis after injury. Biochem. Soc. Trans. 2003, 31, 335-336.

(2) Sandvig, A.; Berry, M.; Barrett, L. B.; Butt, A.; Logan, A. Myelin-, reactive glia-, and scar-derived $\mathrm{CNS}$ axon growth inhibitors: expression, receptor signaling, and correlation with axon regeneration. Glia 2004, 46, 225-251.

(3) Tran, A. P.; Warren, P. M.; Silver, J. The Biology of Regeneration Failure and Success After Spinal Cord Injury. Physiol. Rev. 2018, 98, 881-917.

(4) Yamagata, T.; Saito, H.; Habuchi, O.; Suzuki, S. Purification and properties of bacterial chondroitinases and chondrosulfatases. J. Biol. Chem. 1968, 243, 1523-1535.

(5) Huang, W.; Matte, A.; Suzuki, S.; Sugiura, N.; Miyazono, H.; Cygler, M. Crystallization and preliminary X-ray analysis of chondroitin sulfate $\mathrm{ABC}$ lyases I and II fromProteus vulgaris. Acta Crystallogr., Sect. D: Biol. Crystallogr. 2000, 56, 904-906.

(6) Prabhakar, V.; Raman, R.; Capila, I.; Bosques, C. J.; Pojasek, K.; Sasisekharan, R. Biochemical characterization of the chondroitinase ABC I active site. Biochem 2005, 390, 395-405.

(7) Huang, W.-C.; Kuo, W.-C.; Cherng, J.-H.; Hsu, S.-H.; Chen, P.R.; Huang, S.-H.; Huang, M.-C.; Liu, J.-C.; Cheng, H. Chondroitinase $\mathrm{ABC}$ promotes axonal re-growth and behavior recovery in spinal cord injury. Biochem. Biophys. Res. Commun. 2006, 349, 963-968.

(8) McKeon, R. J.; Höke, A.; Silver, J. Injury-induced proteoglycans inhibit the potential for laminin-mediated axon growth on astrocytic scars. Exp. Neurol. 1995, 136, 32-43.

(9) Zuo, J.; Neubauer, D.; Dyess, K.; Ferguson, T. A.; Muir, D. Degradation of chondroitin sulfate proteoglycan enhances the neuritepromoting potential of spinal cord tissue. Exp. Neurol. 1998, 154, 654-662.

(10) Moon, L. D. F.; Asher, R. A.; Rhodes, K. E.; Fawcett, J. W. Regeneration of CNS axons back to their target following treatment of adult rat brain with chondroitinase ABC. Nat. Neurosci. 2001, 4, 465466.
(11) Bradbury, E. J.; Moon, L. D. F.; Popat, R. J.; King, V. R.; Bennett, G. S.; Patel, P. N.; Fawcett, J. W.; McMahon, S. B. Chondroitinase $\mathrm{ABC}$ promotes functional recovery after spinal cord injury. Nature 2002, 416, 636-640.

(12) Pizzorusso, T.; Medini, P.; Berardi, N.; Chierzi, S.; Fawcett, J. W.; Maffei, L. Reactivation of ocular dominance plasticity in the adult visual cortex. Science 2002, 298, 1248-1251.

(13) Warren, P. M.; Steiger, S. C.; Dick, T. E.; MacFarlane, P. M.; Alilain, W. J.; Silver, J. Rapid and robust restoration of breathing long after spinal cord injury. Nat. Commun. 2018, 9, 4843.

(14) Tropea, D.; Caleo, M.; Maffei, L. Synergistic effects of brainderived neurotrophic factor and chondroitinase $A B C$ on retinal fiber sprouting after denervation of the superior colliculus in adult rats. $J$. Neurosci. 2003, 23, 7034-7044.

(15) Yick, L. Axonal regeneration of Clarke's neurons beyond the spinal cord injury scar after treatment with chondroitinase ABC. Exp. Neurol. 2003, 182, 160-168.

(16) Caggiano, A. O.; Zimber, M. P.; Ganguly, A.; Blight, A. R.; Gruskin, E. A. Chondroitinase ABCI improves locomotion and bladder function following contusion injury of the rat spinal cord. J. Neurotrauma 2005, 22, 226-239.

(17) Cafferty, W. B. J.; Bradbury, E. J.; Lidierth, M.; Jones, M.; Duffy, P. J.; Pezet, S.; McMahon, S. B. Chondroitinase ABC-Mediated Plasticity of Spinal Sensory Function. J. Neurosci. 2008, 28, 1199812009.

(18) Lin, R.; Kwok, J. C. F.; Crespo, D.; Fawcett, J. W. Chondroitinase $\mathrm{ABC}$ has a long-lasting effect on chondroitin sulphate glycosaminoglycan content in the injured rat brain. J. Neurochem. 2007, 104, 400-408.

(19) Tester, N. J.; Plaas, A. H.; Howland, D. R. Effect of body temperature on chondroitinase $\mathrm{ABC}$ 's ability to cleave chondroitin sulfate glycosaminoglycans. J. Neurosci. Res. 2007, 85, 1110-1118.

(20) Iseda, T.; Okuda, T.; Kane-Goldsmith, N.; Mathew, M.; Ahmed, S.; Chang, Y.-W.; Young, W.; Grumet, M. Single, High-Dose Intraspinal Injection of Chondroitinase Reduces Glycosaminoglycans in Injured Spinal Cord and Promotes Corticospinal Axonal Regrowth after Hemisection but Not Contusion. J. Neurotrauma 2008, 25, 334349.

(21) Tom, V. J.; Kadakia, R.; Santi, L.; Houlé, J. D. Administration of chondroitinase $\mathrm{ABC}$ rostral or caudal to a spinal cord injury site promotes anatomical but not functional plasticity. J. Neurotrauma 2009, 26, 2323-2333.

(22) Fuller, D. D.; Lee, K.-Z.; Tester, N. J. The impact of spinal cord injury on breathing during sleep. Respir. Physiol. Neurobiol. 2013, 188, 344-354.

(23) Tauchi, R.; Imagama, S.; Natori, T.; Ohgomori, T.; Muramoto, A.; Shinjo, R.; Matsuyama, Y.; Ishiguro, N.; Kadomatsu, K. The endogenous proteoglycan-degrading enzyme ADAMTS-4 promotes functional recovery after spinal cord injury. J. Neuroinflammation 2012, 9, 53

(24) Pakulska, M. M.; Tator, C. H.; Shoichet, M. S. Local delivery of chondroitinase $\mathrm{ABC}$ with or without stromal cell-derived factor $1 \alpha$ promotes functional repair in the injured rat spinal cord. Biomaterials 2017, 134, 13-21.

(25) Hyatt, A. J. T.; Wang, D.; Kwok, J. C.; Fawcett, J. W.; Martin, K. R. Controlled release of chondroitinase $A B C$ from fibrin gel reduces the level of inhibitory glycosaminoglycan chains in lesioned spinal cord. J. Controlled Release 2010, 147, 24-29.

(26) Azizi, M.; Farahmandghavi, F.; Joghataei, M. T.; Zandi, M.; Imani, M.; Bakhtiari, M.; Omidian, H. ChABC-loaded PLGA nanoparticles: A comprehensive study on biocompatibility, functional recovery, and axonal regeneration in animal model of spinal cord injury. Int. J. Pharm. 2020, 577, 119037.

(27) Cafferty, W. B. J.; Yang, S.-H.; Duffy, P. J.; Li, S.; Strittmatter, S. M. Functional Axonal Regeneration through Astrocytic Scar Genetically Modified to Digest Chondroitin Sulfate Proteoglycans. J. Neurosci. 2007, 27, 2176-2185.

(28) Muir, E. M.; Fyfe, I.; Gardiner, S.; Li, L.; Warren, P.; Fawcett, J. W.; Keynes, R. J.; Rogers, J. H. Modification of N-glycosylation sites 
allows secretion of bacterial chondroitinase $\mathrm{ABC}$ from mammalian cells. J. Biotechnol. 2010, 145, 103-110.

(29) Warren, P. M.; Andrews, M. R.; Smith, M.; Bartus, K.; Bradbury, E. J.; Verhaagen, J.; Fawcett, J. W.; Kwok, J. C. F. Secretion of a mammalian chondroitinase $\mathrm{ABC}$ aids glial integration at PNS/ CNS boundaries. Sci. Rep. 2020, 10, 11262.

(30) Day, P.; Alves, N.; Daniell, E.; Dasgupta, D.; Ogborne, R.; Steeper, A.; Raza, M.; Ellis, C.; Fawcett, J.; Keynes, R.; Muir, E. Targeting chondroitinase $\mathrm{ABC}$ to axons enhances the ability of chondroitinase to promote neurite outgrowth and sprouting. PLoS One 2020, 15, No. e0221851.

(31) Bartus, K.; James, N. D.; Didangelos, A.; Bosch, K. D.; Verhaagen, J.; Yáñez-Muñoz, R. J.; Rogers, J. H.; Schneider, B. L.; Muir, E. M.; Bradbury, E. J. Large-scale chondroitin sulfate proteoglycan digestion with chondroitinase gene therapy leads to reduced pathology and modulates macrophage phenotype following spinal cord contusion injury. J. Neurosci. 2014, 34, 4822-4836.

(32) Burnside, E. R.; De Winter, F.; Didangelos, A.; James, N. D.; Andreica, E.-C.; Layard-Horsfall, H.; Muir, E. M.; Verhaagen, J.; Bradbury, E. J. Immune-evasive gene switch enables regulated delivery of chondroitinase after spinal cord injury. Brain 2018, 141, 2362.

(33) Prabhakar, V.; Capila, I.; Bosques, C. J.; Pojasek, K.; Sasisekharan, R. Chondroitinase ABC I from Proteus vulgaris: cloning, recombinant expression and active site identification. Biochem 2005, 386, 103-112.

(34) Prabhakar, V.; Capila, I.; Raman, R.; Srinivasan, A.; Bosques, C. J.; Pojasek, K.; Wrick, M. A.; Sasisekharan, R. The Catalytic Machinery of Chondroitinase ABC I Utilizes a Calcium Coordination Strategy to Optimally Process Dermatan Sulfate†. Biochem 2006, 45, $11130-11139$.

(35) Hiyama, K.; Okada, S. Action of Chondroitinases. J. Biochem. 1976, 80, 1201-1207.

(36) Klüppel, M. Efficient secretion of biologically active Chondroitinase $\mathrm{ABC}$ from mammalian cells in the absence of an $\mathrm{N}$ terminal signal peptide. Mol. Cell. Biochem. 2011, 351, 1-11.

(37) Guo, Y.; Klüppel, M.; Tang, H.; Tan, S.; Zhang, P.; Chen, Z. Lentivirus-mediated transfection of chondroitinase $A B C$ gene without the bacterial leader sequence enables long-term secretion of functional chondroitinase $\mathrm{ABC}$ in human bone marrow stromal cells. Biotechnol. Lett. 2016, 38, 893-900.

(38) Coulson-Thomas, Y. M.; Coulson-Thomas, V. J.; Filippo, T. R.; Mortara, R. A.; da Silveira, R. B.; Nader, H. B.; Porcionatto, M. A. Adult bone marrow-derived mononuclear cells expressing chondroitinase AC transplanted into CNS injury sites promote local brain chondroitin sulphate degradation. J. Neurosci. Methods 2008, 171, 1929.

(39) Jin, Y.; Ketschek, A.; Jiang, Z.; Smith, G.; Fischer, I. Chondroitinase activity can be transduced by a lentiviral vector in vitro and in vivo. J. Neurosci. Methods 2011, 199, 208-213.

(40) Curinga, G. M.; Snow, D. M.; Mashburn, C.; Kohler, K.; Thobaben, R.; Caggiano, A. O.; Smith, G. M. Mammalian-produced chondroitinase AC mitigates axon inhibition by chondroitin sulfate proteoglycans. J. Neurochem. 2007, 102, 275-288.

(41) Kwok, J. C. F.; Afshari, F.; García-Alías, G.; Fawcett, J. W. Proteoglycans in the central nervous system: plasticity, regeneration and their stimulation with chondroitinase ABC. Restor. Neurol. Neurosci. 2008, 26, 131-145.

(42) Properzi, F.; Carulli, D.; Asher, R. A.; Muir, E.; Camargo, L. M.; van Kuppevelt, T. H.; ten Dam, G. B.; Furukawa, Y.; Mikami, T.; Sugahara, K.; Toida, T.; Geller, H. M.; Fawcett, J. W. Chondroitin 6sulphate synthesis is up-regulated in injured CNS, induced by injuryrelated cytokines and enhanced in axon-growth inhibitory glia. Eur. J. Neurosci. 2005, 21, 378-390.

(43) Shaya, D.; Hahn, B.-S.; Park, N. Y.; Sim, J.-S.; Kim, Y. S.; Cygler, M. Characterization of Chondroitin Sulfate Lyase ABC fromBacteroides thetaiotaomicronWAL2926 $\dagger$. Biochem 2008, 47, 6650-6661.

(44) Lee, H.; McKeon, R. J.; Bellamkonda, R. V. Sustained delivery of thermostabilized chABC enhances axonal sprouting and functional recovery after spinal cord injury. Proc. Natl. Acad. Sci. U.S.A. 2010, $107,3340-3345$.

(45) Alves, J. N.; Muir, E. M.; Andrews, M. R.; Ward, A.; Michelmore, N.; Dasgupta, D.; Verhaagen, J.; Moloney, E. B.; Keynes, R. J.; Fawcett, J. W.; Rogers, J. H. AAV vector-mediated secretion of chondroitinase provides a sensitive tracer for axonal arborisations. $J$. Neurosci. Methods 2014, 227, 107-120. 